\title{
Stage I Cervical Cancer AJCC v6 and v7
}

National Cancer Institute

\section{Source}

National Cancer Institute. Stage I Cervical Cancer A/CC v6 and v7. NCI Thesaurus. Code C9204.

Stage I includes: I (T1, N0, M0); IA (T1a, N0, M0); IA1 (T1a1, N0, M0); IA2 (T1a2, N0, M0); IB (T1b, N0, M0); IB1(T1b1, N0, M0); IB2 (T1b2, N0, M0). T1: Cervical carcinoma confined to uterus (extension to corpus should be disregarded). T1a: Invasive carcinoma diagnosed only by microscopy. Stromal invasion with a maximum depth of $5.0 \mathrm{~mm}$ measured from the base of the epithelium and a horizontal spread of $7.0 \mathrm{~mm}$ or less. Vascular space involvement, venous or lymphatic, does not affect classification. T1a1: Measured stromal invasion $3.0 \mathrm{~mm}$ or less in depth and 7.0 or less horizontal spread. T1a2: Measured stromal invasion more than $3.0 \mathrm{~mm}$ and not more than $5.0 \mathrm{~mm}$ with a horizontal spread $7.0 \mathrm{~mm}$ or less. T1b: Clinically visible lesion confined to the cervix or microscopic lesion greater than T1a/IA2. T1b1: Clinically visible lesion $4.0 \mathrm{~cm}$ or less in greatest dimension. T1b2: Clinically visible lesion more than $4.0 \mathrm{~cm}$ in greatest dimension. NO: No regional lymph node metastasis. M0: No distant metastasis. (AJCC 6th and 7th eds.) 